https://www.journal-imab-bg.org

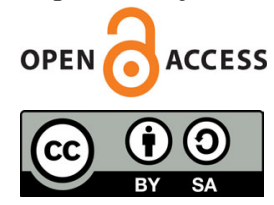

Original article

\title{
INVESTIGATION OF HEALTH EFFECT OF FRUIT JUICE FROM LINGONBERRY (VACCINIUM VITIS - IDEA) VIA PHYSICOCHEMICAL METHODS
}

\author{
Poli Radusheva ${ }^{1}$, Iliana Milkova-Tomova ${ }^{2}$, Krastena Nikolova ${ }^{1}$, Dragomira \\ Buhalova $^{2}$, Jordanka Aleksieva ${ }^{2}$, Tinko Eftimov ${ }^{3}$, Stefan Krustev ${ }^{1}$ \\ 1 )Department of Physics and Biophysics, Faculty of Pharmacy, Medical University \\ - Varna, Bulgaria \\ 2) Department of Food and Tourism, Faculty of Economics, University of Food \\ Technologies - Plovdiv, Bulgaria \\ 3) Departement d'informatique et d'ingénierie, Université du Québec en Outaouais- \\ Gatienau, Québec, Canada
}

ABSTRACT:

Objective: Antioxidants reduce cell damaging effects of free radicals, they also are used as medications to treat various forms of brain injury. Forest fruits as a lingonberry contain a lot of flavonoids and antioxidant supplements which contribute to the protection of different types of cancers and cardiovascular health problems.

Purpose: The aim of this study is to explore the relations between natural fluorescence in juice from lingonberry and its total phenolic content and total antioxidant capacity in view of the usefulness of these compounds for human health and hygiene of food.

Materials and Methods: For this reason, the juices from lingonberry from the region of Velingrad ånriched with lactulose will be investigated by using optical methods (colour measuring, fluorescence spectroscopy), rheological properties and sensor analysis. It may be an alternative method for quantifying the phenols and vitamins in juice from wild berries.

Results: The dependences between chemical parameters, colour characteristics and the ratio between the intensity of emission and the intensity of excitation for exciting wavelength $275 \mathrm{~nm}$ have been found. The dependence between antioxidant activity and total phenolic content also exists. Excitation in the UV region is suitable for distinguishing the phenolic content and antioxidant compounds. The most suitable wavelengths found to be $265 \mathrm{~nm}$ and 275 $\mathrm{nm}$. Lingonberry juices with lactulose exhibited nonNewtonian behaviour and Ostwald-de-Waele model are applied to calculate its rheological properties.

Conclusions: The natural fluorescence of the lingonberry juices was correlated with their antioxidant properties, total phenolic content and lightness.

From fluorescence spectra three groups of fluorescence components are determined - phenolic acids, tannins and flavonoids.

The obtained results and discussion presented here give the direction for further studies and additional test for validation of the correlation between fluorescence inten- sity and phenolic compounds. In the future investigation, the fluorescence in the visible region will be used for determining the content of vitamins. The fluorescence spectroscopy is a promising technique for the rapid screening of lingonberry juice for antioxidant and phenolic content.

The rheological behaviour of pasteurised juice from lingonberry showed a pseudoplastic behaviour.

Keywords: juice, lingonberry, fluorescence spectroscopy, phenolic content, antioxidative activity, rheology

\section{INTRODUCTION:}

Lingonberries (Vaccinium vitis-idaea) are kind of bushes or subshrubs of Pyrene family, which are distributed in wide regions of the Northern countries such as Finland, Sweden and Norway. Its fruits are used for consumption as juice, jam, wine or tea. There is a growing interest in the investigation of fruits because they contain bioactive compounds such as phenolic compounds [1-3], anthocyanins, omega-3 fatty acids, vitamins [4]. These compounds have nutritional and medical application - they stimulate the immune system, modulating hormone metabolism and possess antibacterial and antiviral action [5-7]. In the numerous studies, authors reported that the foods from lingonberry could reduce the incidence of cancer, cataracts, macular degeneration and cardiovascular disease [8-9]. There are many methods to determine the phenolic content and antioxidant activity of berries juice - the most frequently used are high performance liquid chromatography (HPLC), mass spectrometry and fluorimetry [10-11]. In literature, there are reports that fluorescence spectroscopy is used to screen the antioxidant contents in coffee and tomato paste [12-13].

The aim of this study is to explore the relations between natural fluorescence in juice from lingonberry and its total phenolic content and total antioxidant capacity in view of the usefulness of these compounds for human health and hygiene of food. Front face fluorescence spectroscopy is a quick, non time consuming method with high selectivity and 
sensitivity, without the use of chemical reagents. It may be an alternative method for quantifying the phenols and vitamins in juice from wild berries.

\section{MATERIALS AND METHODS:}

Samples and technologies:

The investigation used wild fruits Vaccinium vitisidaea L. from harvest 2015 in the region of Velingrad. The juice from lingonberry ånriched with polyphenols is obtained by using the technological scheme, which is presented in Figure 1. The pasteurised juices with adding of lactulose are investigated.

Fig. 1. Technological scheme for producing pressed juice

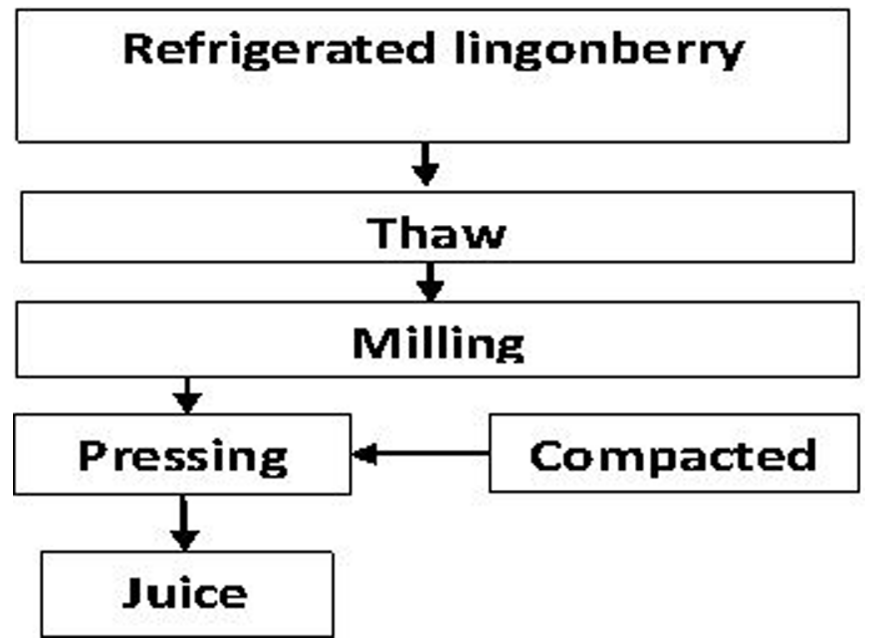

METHODS:

The content of polyphenols and anthocyanins 0.5 $1 \mathrm{ml}$ fresh plant material was triturated with quartz sand and $2-5 \mathrm{ml} 70 \%$ methanol in a mortar, quantitatively transferred to a flask with a reflux refrigerator. It is extracted for $20 \mathrm{~min}$ at $70^{\circ} \mathrm{C}$ three times. The content of anthocyanin pigment concentration expressed as cyanidin-3-glucose equivalent, is calculated. The contents of biologically active substances such as anthocyanin and phenolic components in the juice samples were measured spectrophotometrically.

Antioxidant activity: Ferric reducing antioxidant power (FRAP) assay was used for determining the antioxidant activity. The reaction was started by mixing $3.0 \mathrm{ml}$
FRAP reagent with $0.1 \mathrm{ml}$ of investigated juice. The reaction time was $10 \mathrm{~min}$ at $37^{\circ} \mathrm{C}$ in darkness, and the absorbance was measured at $593 \mathrm{~nm}$.

Fluorescence spectra measurements: The sources used to measure the fluorescence spectra are $245 \mathrm{~nm}, 265$ $\mathrm{nm}, 275 \mathrm{~nm}$ and $295 \mathrm{~nm}$ light emitting diodes (LEDs). A fiber optic spectrometer (AvaSpec-2038, Avantes) with a sensitivity in the (200-1100) nm range and a resolution of about $8 \mathrm{~nm}$ was used to measure the fluorescence spectra. The lingonberry juices were placed in a cuvette $10 \mathrm{~mm}$ x $10 \mathrm{~mm}$ and illuminated by LEDs.

Determination of rheological characteristics: The rheological profiles of the investigated samples were measured by using Brookfield viscometer (Brookfield Engineering Laboratories: model LVDV-II + PRO). The rheological data obtained for lingonberry juice were fitted to Newton model:

$$
\begin{aligned}
& \boldsymbol{\sigma}=\boldsymbol{\eta} \cdot \boldsymbol{\gamma} \\
& \text { and Ostwald-de-Waele model } \\
& \boldsymbol{\sigma}=\boldsymbol{K} \cdot \boldsymbol{\gamma}^{\boldsymbol{n}}
\end{aligned}
$$

Where $\sigma$ is shear stress, $\gamma$ is the shear rate, $n$ is flow behaviour index, $K$ is consistency.

Colour measuring: Using a software package VISIONlite ColorCalc for spectrophotometer Helios Omega with a cuvette of a $10 \mathrm{~mm}$ length, the colour parameters in CIELab colorimetric system have been obtained. All measurements have been carried out at room temperature. Colour parameters $a, b$ and brightness $L$ of tested samples have been measured. Parameters such as chroma Cab and Hue angle $h_{\mathrm{ab}}$ were defined as follows:

$$
C_{a b}=\sqrt{a^{2}+b^{2}}, h_{a b}=\operatorname{arctg}(b / a)
$$

Sensor analysis: Quantitative descriptive test for sensor profiling is used [14] for determining the sensor characteristics (colour, taste, aftertaste, smell). The corrective estimation is guaranteed from a commission from 12 trained assessors. The intensity of each sensor characteristics are written in the seven balls linear scale.

\section{RESULTS:}

The juice from lingonberry with different concentration of lactulose have been investigated for the total content of anthocyanins and polyphenolic compounds. The results are presented in Table 1. By using FRAP method, the data for antioxidant activity have been obtained (Table 1).

Table 1. Chemical characteristics of juices from lingonberry

\begin{tabular}{|l|c|c|c|}
\hline Sample & $\begin{array}{c}\text { Anthocyanins, } \\
\mathrm{mg} / \mathrm{L}\end{array}$ & $\begin{array}{c}\text { Total polyphenolic content, } \\
\text { mg GAE/L }\end{array}$ & $\begin{array}{c}\text { Antioxidant activity, mMTE/L } \\
\text { (FRAPmethod) }\end{array}$ \\
\hline Juice+Lactulose $0.5 \%$ & 161.65 & 2607.95 & 21554.68 \\
\hline Juice+Lactulose 1\% & 131.59 & 2002.31 & 16175.56 \\
\hline Juice+Lactulose 1.5\% & 121.23 & 1966.47 & 15857.26 \\
\hline
\end{tabular}

The connection exists between investigated chemical parameters in Table 1 and the fluorescence peaks in the visible region. The fluorescence spectra for excitation wave- 
length $245 \mathrm{~nm}, 265 \mathrm{~nm}, 275 \mathrm{~nm}$ and $295 \mathrm{~nm}$ are presented in Figure 2.

Fig. 2. Fluorescence spectra for juices from lingonberry
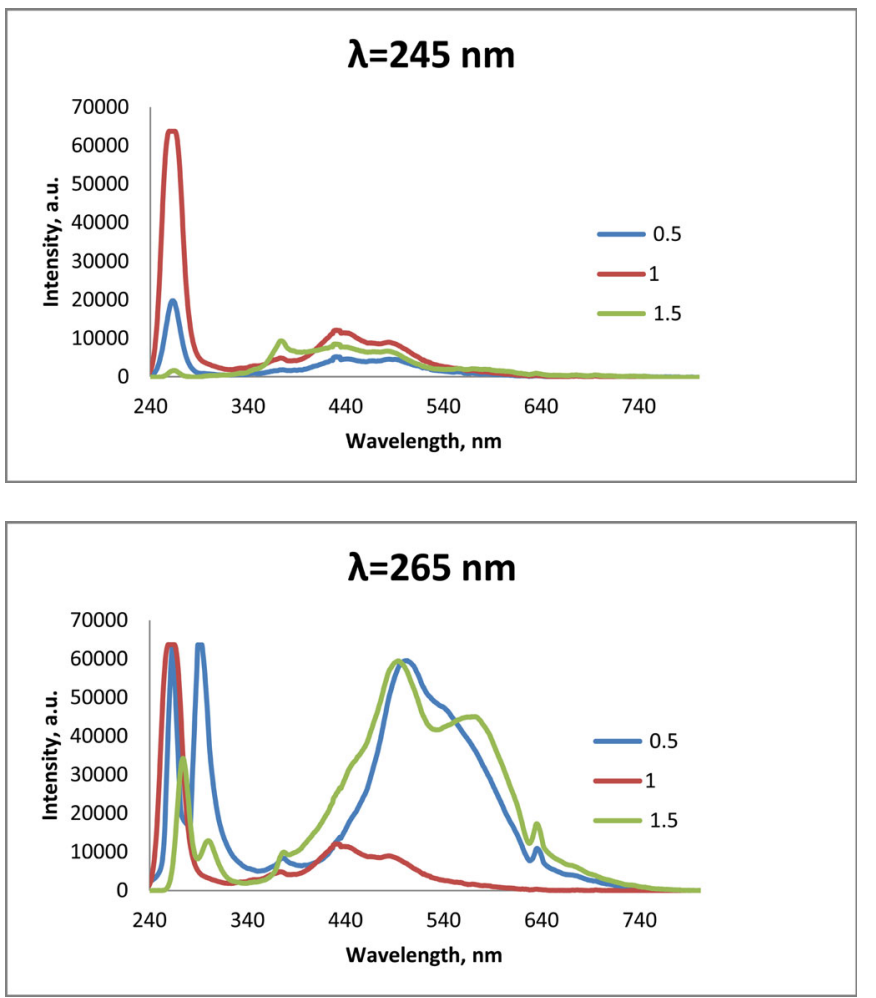
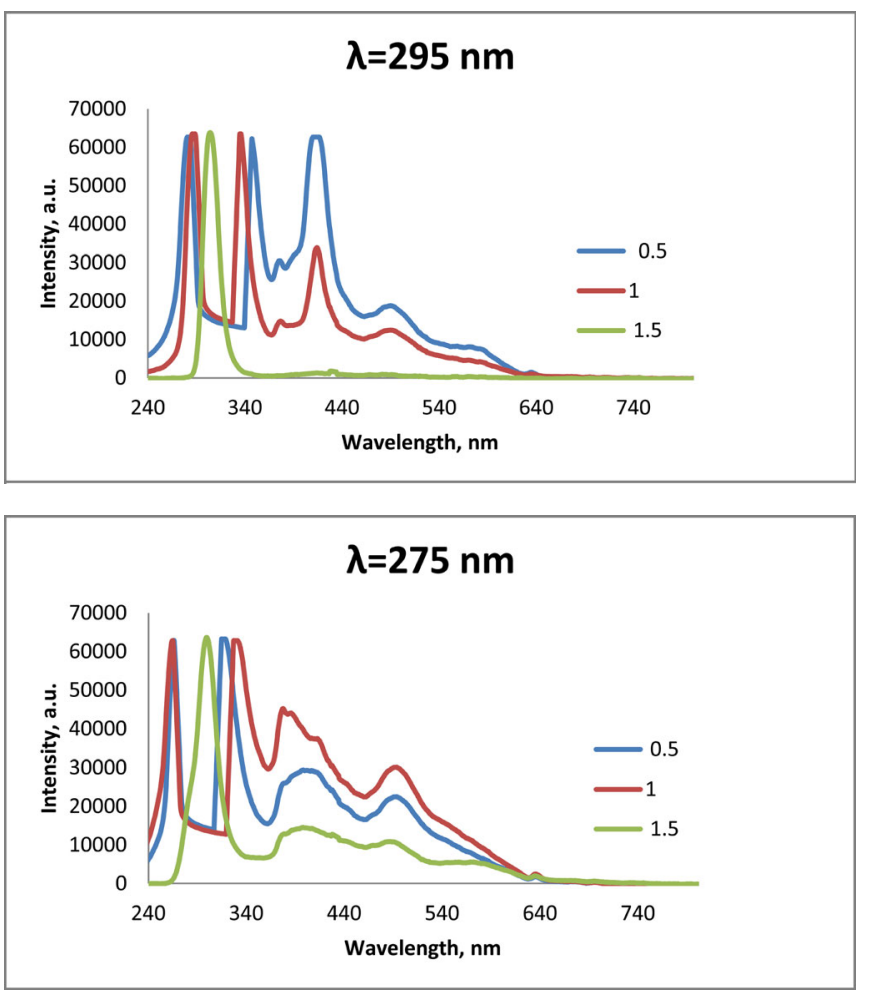

The rheology properties of the juice are investigated by using Ostwald-de Waele model. The results for the consistency index $(\mathrm{K})$ and the flow behaviour index (n) are obtained in Table 2.

Table 2. Predicted parameters for juice from lingonberry for Ostwald-de Waele model

\begin{tabular}{|l|c|c|c|}
\hline Type of juice & $\mathbf{K},\left(\boldsymbol{P a}_{\mathbf{s}} \boldsymbol{n}^{\boldsymbol{}}\right.$ & $\mathbf{n}$ & $\boldsymbol{R}^{\mathbf{2}}$ \\
\hline $0.5 \%$ lactulose & 166.68 & 0.653 & 0.999 \\
\hline $1 \%$ lactulose & 14.92 & 0.803 & 0.997 \\
\hline $1.5 \%$ lactulose & 20.53 & 0.812 & 0.998 \\
\hline
\end{tabular}

Colour characteristics in CIE Lab colorimetric system have been measured (Table 3). The dependencies between chemical parameters, colour characteristics and the ratio between the intensity of emission and intensity of ex- citation for exciting wavelength $275 \mathrm{~nm}$ have been found. The dependence between antioxidant activity and total phenolic content also exists. The existing dependencies and its correlation coefficients are presented in Table 4.

Table 3. Colour parameters in CIE Lab systems for lingonberry juices

\begin{tabular}{|l|c|c|c|c|c|}
\hline Type of juice & $\mathrm{L}$ & $\mathrm{a}$ & $\mathrm{b}$ & $h_{a, b}$ & $C_{a, b}$ \\
\hline $0.5 \%$ lactulose & 21.88 & 15.16 & 1.17 & 4.41 & 15.21 \\
\hline $1 \%$ lactulose & 20.76 & 11.35 & 0.65 & 3.28 & 11.37 \\
\hline $1.5 \%$ lactulose & 21.13 & 12.29 & 1.01 & 12.33 & 4.70 \\
\hline
\end{tabular}


Table 4. Dependences between chemical parameters and optical characteristics

\begin{tabular}{|l|c|}
\hline Dependence & $R^{2}$ \\
\hline Total phenolic content $(\mathrm{TPC})$ and anthocyanins $(\mathrm{A})-T P C=-132.66+16.83 \times A$ & 0.96 \\
\hline Antioxidant activity $(\mathrm{AA})$ and total phenolic content $(\mathrm{TPC})-A A=8.88 \times T P C-1609.2$ & 1 \\
\hline Total phenolic content and the ratio $\mathrm{I}_{\text {emission }} / \mathrm{I}_{\text {exitation }}$ for exiting wavelength $275 \mathrm{~nm}$. & 0.99 \\
$T P C=1750+262.20 \times \frac{I_{\text {emission }}}{I_{\text {exitation }}}$ & \\
\hline $\begin{array}{l}\text { Lightness of the samples and the ratio } \mathrm{I}_{\text {emission }} / \mathrm{I}_{\text {exitation }} \text { for exiting wavelength } 275 \mathrm{~nm} \\
\frac{I_{\text {emission }}}{I_{\text {exitation }}}=-20.31+0.99 \times L\end{array}$ & 0.94 \\
\hline
\end{tabular}

The results from sensor analysis have been presented in Figure 3, where samples 1, 2 and 3 correspond to juices with $0.5 \%, 1 \%$ and $1.5 \%$ concentration of lactulose.

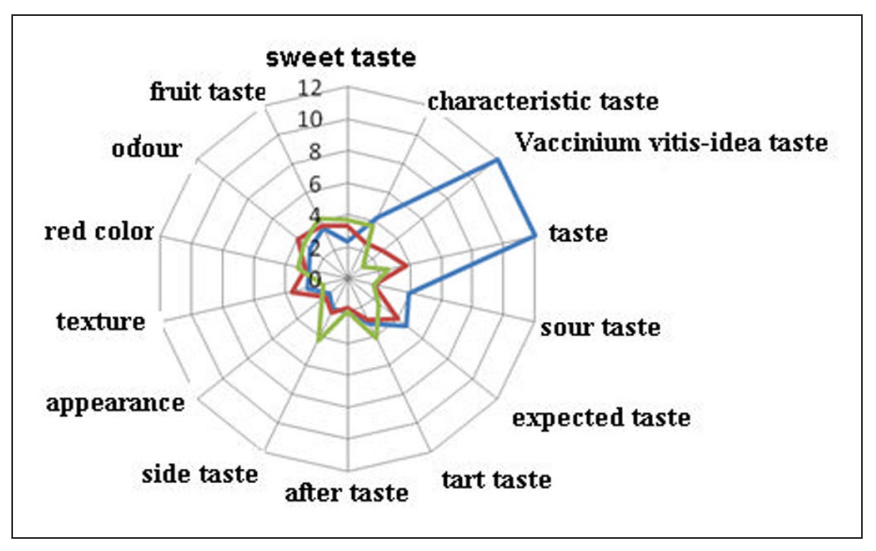

Fig. 3. Diagram from sensor analysis

Fig. 4. Flow curves and viscosity curves of pasteurised lingonberry juice
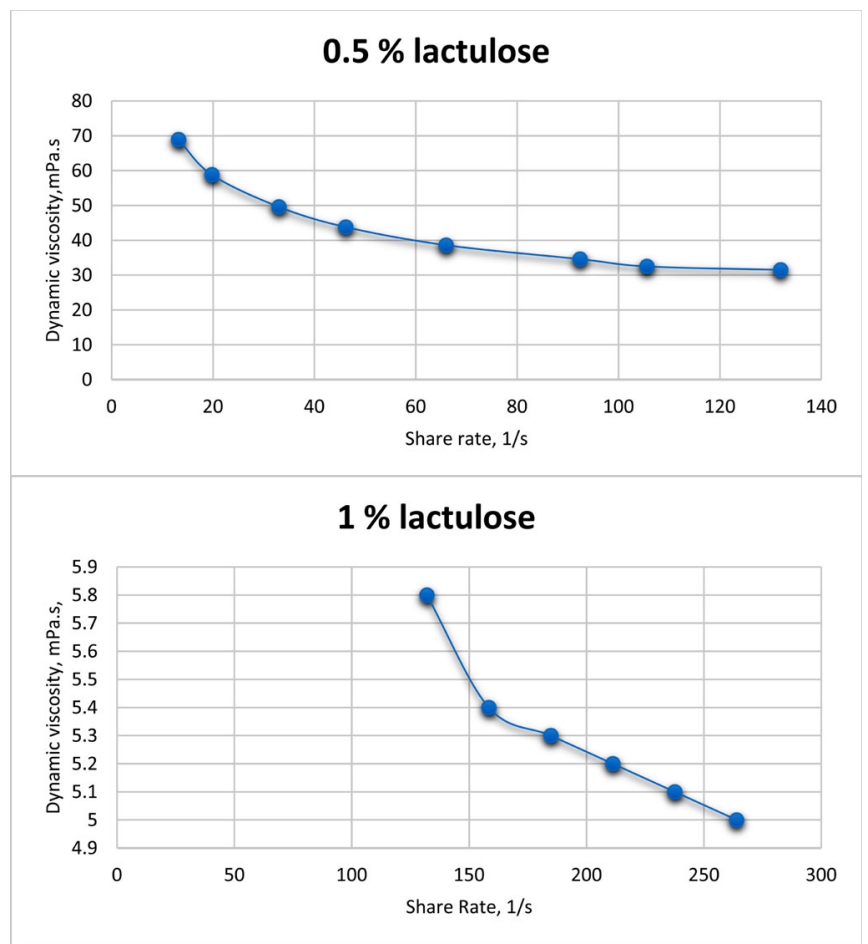

\section{DISCUSSION:}

The research is focused on juices of wild berries and more specifically on cranberry juice. We have searched for relations between chemical compounds having importance

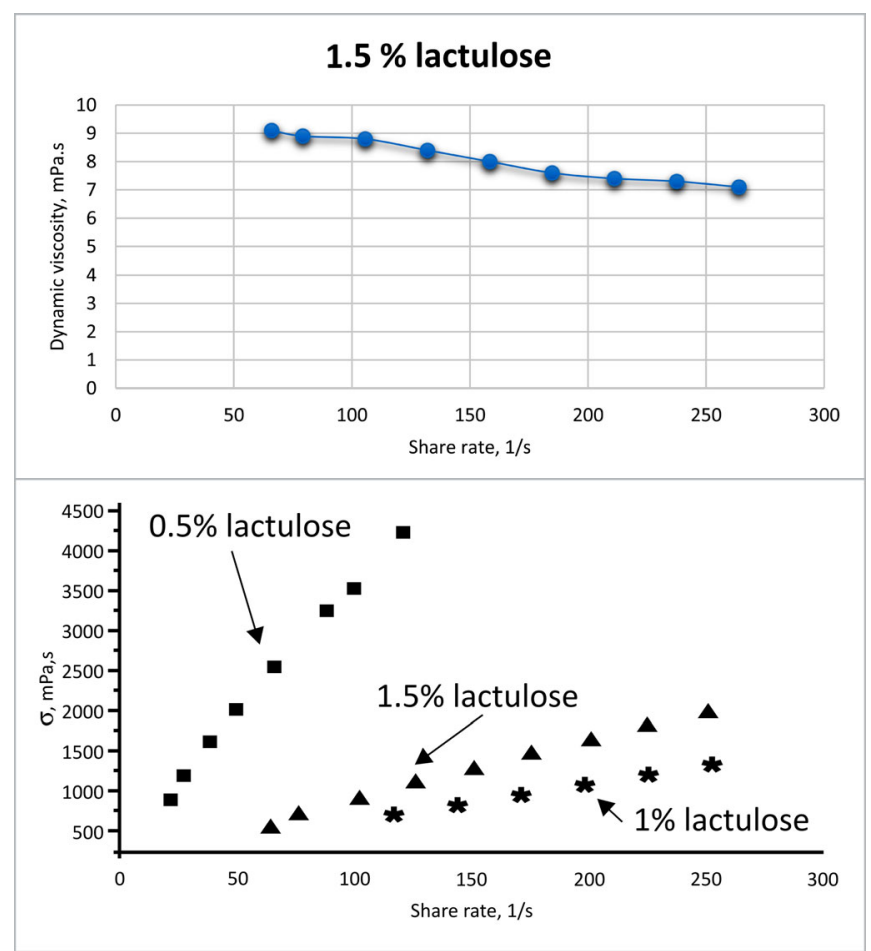

for healthy food and the proper functioning of human body organs on the one side and optical parameters, permitting a quick quality analysis of the above compounds. 
The content of the polyphenol acids in cranberry juice is of high significance because they stimulate the proper functioning of digestive system helping the rational use of food, improve appetite, decrease the intake of excessive quantities of water, thus exercising a beneficial effect in the case of disorders of the digestive system. The contents of tannin in these fruits makes them have an antiinflammatory effect and an excellent antidiarrhetic, especially in some cases of catarrhal colitis. The role of cranberry for the proper flow of vital processes due to the vitamins, phytoncides organic acids, vegetable hormones, carbohydrates, pectin and aroma substances, enzymes, causing antioxidant activity of juices and their fluorescence. There is a variety of data in medical science that the presence of the above compounds in cranberry juice is the cause of its tonic, refreshing effect which increases human activity.

It is evident from Figure 2 that the emission intensity has the lowest value for excitation wavelength $245 \mathrm{~nm}$. The fluorescence spectra are clearly distinguishable for $275 \mathrm{~nm}$, and the ratio between excitation and emission intensities is the best for a $265 \mathrm{~nm}$ excitation wavelength. The pointed wavelengths are appropriate for determining the fluorescence components in juice from lingonberry. Phenolic acids have the adbsorption maxima in the 240 $\mathrm{nm}-290 \mathrm{~nm}$ range, and the excitation/emission intervals are observed as follows:

1. $245 \mathrm{~nm} / 445 \mathrm{~nm}$ - it is connected with the chlorogenic acid in juice with $0.5 \%$ and $1.5 \%$ lactulose. The similar results have been obtained in [14] from Mazina et al. for the apple juice.

2. $265 \mathrm{~nm} / 426 \mathrm{~nm}$ - this is maximum for $1.5 \%$ lactulose in juice from lingonberry, and this maximum is belonged to caffeic acids [15].

3. $(230 \mathrm{~nm}-315) \mathbf{n m} /(\mathbf{3 4 5}-405)$ in literature connected with tannins acids. This maximum is observed for all of the concentration of lactulose in the investigated juice.

4. $275 \mathrm{~nm} /(\mathbf{3 2 0 - 3 3 5}) \mathbf{n m}$ is maximum for catechin and epicatechin [16].

The proposed method for obtaining the fluorescence spectra is very simple, developed compactly and cost effective, because the system uses LED light sources, which are cheaper than lasers and they can cover the range from deep UV to visible light. In the present study, the excitation wavelength in the UV range is used because the goal is to find qualitatively the phenols and anthocyanins. The excitation wavelength in the visible region will be used in the future investigation for qualitative determination for vitamins because they are also important for human health.

It is evident that the antioxidant activity decreases with raising the concentration of lactulose. Juices from lingonberry contain flavonoids, low molecular weight polyphenols, anthocyanins, which have an anticarcinogenic effect, anti allergic, antiviral and anticancer activity [17]. They have a greater content of antioxidants than grapes at about 12\% [18]. Antioxidant activity of juices from lingonberry is due to the polyphenolic contents. These components help in the prevention of cardiovascular diseases, in treatments for Neurodegenerative diseases and amylotrophic lateral sclerosis [19]. The total phenolic content of juice from lingonberry with $0.5 \%$ lactulose is two times lower than the juice from aronia melanocarpa [18].

The fluorescence spectroscopy is an advanced technique for the rapid screening of lingonberry juices for total phenolic contents. It is found that the dependence between ratio intensity of fluorescence and intensity of excitation for wavelength $275 \mathrm{~nm}$ and total phenolic content exist. A positive correlation was obtained between phenols and antioxidant activity. The similar relation is in accordance with literature data for apple juice [19].

The investigated juices have low brightness in the interval (20-22) a.u. with dominant red and yellow colors and with sharp Hue angle less than $15^{\circ}$. There is a positive correlation between brightness and the ratio of intensities of emission and excitation for wavelength $275 \mathrm{~nm}$. Adding of lactulose slightly changed the brightness of the juices.

The taste profile is developed of fruit juices from lingonberry with lactulose, and the sensor analysis is made on the basis of the main indicators. The appearances and cranberry flavor are highlighted in the first sample. The low concentration of lactulose in juice is acceptable for consumers, and the juice is close to natural.

The rheological properties are very important for hygiene of food because they are changed dramatically [20] for different concentration levels during processing of fruit juices. In Figure 4 were shown flow and viscosity curves of pasteurized lingonberry juice. In this case, rheograms of viscosity versus shear rate show concave curves. This fact shows that lingonberry juices with lactulose exhibited non-Newtonian behavior and Ostwald-de-Waele model are applied to calculate its rheological properties. All the values of the flow behavior index are below 1 supporting the pseudoplastic behaviour of pasteurized juice (Table 3). The same results have been reported from Kobus et all. for juice from carrots [21]. The index of consistency is greater for the juice with $0.5 \%$ lactulose and index of flow behavior.

\section{CONCLUSION}

The natural fluorescence of the lingonberry juices was correlated with their antioxidant properties, total phenolic content and lightness. From fluorescence spectra three groups of fluorescence components are determined - phenolic acids, tannins and flavonoids. The obtained results and discussion presented here give the direction for further studies and an additional test for validation of the correlation between fluorescence intensity and phenolic compounds. In the future investigation, the fluorescence in the visible region will be used for determining the content of vitamins. It can be concluded that the fluorescence spectroscopy is a promising technique for the rapid screening of lingonberry juice for antioxidant and phenolic content.

The rheological behaviour of pasteurized juice from lingonberry showed a pseudoplastic behaviour. The pasteurization process can change not only the viscosity but also the rheological properties of lingonberry juice. 


\section{REFERENCES:}

1. Kylli P, Nohynek L, PuupponenPimia R, Wasterlund-Wikstrom B, Leppanen T, Welling J, et al. Lingonberry (Vaccinium vitis-idaea) and European cranberry (Vaccinium microcarpon) proanthocyanidins: isolation, identification, and bioactivities. $J$ Agric Food Chem. 2011 Apr 13;59(7): 3373-84. [PubMed] [CrossRef]

2. Kalt W, MacKinnon S, McDonald J, Vingvist M, Craft C, Howell A. Phenolic of Vaccinium berries and other fruit crops. J Sci Food Agric. 2008 Jan;88(1):68-76. [CrossRef]

3. Hellstrom JK, Torronen AR, Mattila PH. Proanthocyanidins in common food products of plant origin. $J$ Agric Food Chem. 2009 Sep 9; 57(17): 7899-906. [PubMed] [CrossRef]

4. Bere E. Wild berries: A good sourse of $\omega-3$. Eur J Clin Nutr. 2007 Mar; 61(3):431-3. [PubMed] [CrossRef]

5. Vasconcelos SM, Goulart MOF, de França Moura JB, Manfredini V, Benfato Mda S, Kubota LT. [Reactive Oxygen and Nitrogen Species, Antioxidants and Markers of Oxidative Damage in Human Blood: Main Analytical Methods for Their Determination.] [in Portuguese] Quim Nova. 2007 Sep-Oct;30(5):1323-38. [CrossRef]

6. Ribeiro SMR, Queiroz JH, Peluzo MCG, Costa NMB, Matta SLP, Queiroz MELR. [The formation and the effects of the reactive oxygen species in biological media.] [in Portuguese] Biosci J. 2005 Sep-Dec;21(3): 133-149.

7. Szajdek A, Borowska EJ. Bioactive compounds and health-promoting properties of berry fruits: a review. Plant Foods Hum Nutr. 2008 Dec; 63(4):147-56. [PubMed] [CrossRef]

8. Fraser ML, Lee AH, Binns CW.
Lycopene and prostate cancer: emerging evidence. Expert Rev Anticancer Ther. 2005 Oct;5(5):847-854. [PubMed] [CrossRef]

9. Stahl W, Sies H. Bioactivity and protective effects of natural carotenoids. Biochim Biophys Acta. 2005 May 30;1740(2):101-7. [PubMed] [CrossRef]

10. Pyrzynska K, Sentkowska A. Resent development in the HPLC separation of phenolic food compounds. Crit Rev Anal Chem. 2015; 45(1):4151. [CrossRef]

11. Craft BD, Kerrihard AL, Amarowicz R, Pegg RB. Phenol-based antioxidants and the in vitro methods used for their assessment. Compr Rev Food Sci Food Saf. 2012 Mar; 11(2):148-173. [CrossRef]

12. Orzel J, Daszykowski M. A rapid validation of the antioxidant capacity of food commodities based on their fluorescence excitation emission spectra as applicable to coffee and peppermint extracts. Chemometr Intell Lab Syst. 2014 Oct 15:137:74-81. [CrossRef]

13. Orzel J, Stanimirova I, CzarnikMatusewicz B, Daszykowski M. Prediction of the hydrophilic antioxidant capacity of tomato pastes from the IR and fluorescence excitation-emission spectra of extracts and intact samples. Talanta. 2015 Jun 1;138:64-70. [PubMed] [CrossRef]

14. Mazina J, Vaher M, Kuhtinskaja M, Poruvkina L, Kaljurand M. Fluorescence, electrophoretic and chromatographic fingerprints of herbal medicines and their comparative chemometric analysis. Talanta. 2015 Jul 1; 139:233-246. [PubMed] [CrossRef]

15. Alexieva I, Terzieva V,
Buhalova Dr, Milev M, Sapundzhieva T, Milkova I. Food sensory characteristics of traditional Bulgarian fermented beverages based on wild fruits. [Abstract] TFI-2012, Cesena, Italy, October 4-5, 2012. Abstracts Book\&List of Participants. p.99. [Internet]

16. Airado-Rodriguez D, GaleanoDiaz T, Duran-Meras I, Wold JP. Usefulness of fluorescence excitationemission matrices in combination with PARAFAC, as fingerprints of red wines. J Agric Food Chem. 2009 Mar 11; 57(5):1711-20. [PubMed] [CrossRef]

17. Sindhi V, Gupta V, Sharma K, Bhatnagar S, Kumari R, Dhaka N. Potential applications of antioxidants - A review. Journal of Pharmacy Research. 2013 Sept 30;7(9):828-35. [CrossRef]

18. Valcheva-Kuzmanova S, Denev P, Krachanova M, Surleva A, Belcheva A. Composition and antioxidant activity of aronia melanocarpa fruit juice. Varna medical forum. 2014;3:15-20. [in Bulgarian]

19. Gliszczynska-Swiglo A, Tyrakowska B. Quality of commercial apple juices evaluated on the basis of the polyphenol content and the teac antioxidant activity. J Food Science. 2003 Jun;68(5):1844-49. [CrossRef]

20. Kobus Z, Nadulski R, Guz T, Kaminska I. Effect of temperature and concentration on rheological properties of beetroot juice. Technical Sciences. 2014; 17:67-76.

21. Kobus Z, Nadulski R, Guz T, Mazur J, Panasiewicz M. Effect of pasteurization on rheological properties of white carrot juice. Agriculture and Agricultural Science Procedia. 2015; 7:99-102. [CrossRef]

Please cite this article as: Radusheva P, Milkova-Tomova I, Nikolova K, Buhalova D, Aleksieva J, Eftimov T, Krustev $\mathrm{S}$. Investigation of health effect of fruit juice from lingonberry (Vaccinium vitis - idea) via physicochemical methods. $J$ of IMAB. 2017 Oct-Dec;23(4):1731-1736. DOI: https://doi.org/10.5272/jimab.2017234.1731

Address for correspondence:

Krastena Todorova Nikolova,

Department of Physics and Biophysics, Medical University, Varna,

84, Tsar Osvoboditel str., Varna, Bulgaria.

E-mail: kr.nikolova@abv.bg 